\title{
Development of a Tool to Perform Vehicle Road Tests
}

\author{
https://doi.org/10.3991/ijim.v11i5.7071 \\ Manuel Gameiro da Silva $\left({ }^{\square}\right)$ \\ University of Coimbra, Portugal \\ manuel.gameiro@dem.uc.pt \\ Ahmet Gültekin, Eren Ünlütürk \\ Middle East Technical University, Northern Cyprus Campus
}

\begin{abstract}
The development of a tool to analyse data collected in car road tests is presented, allowing a better understanding of the Physics of car motion. Using the measured data of fuel consumption and the main variables related to the vehicle displacement, it is possible to make corrections to the influence of the main disturbing factors and clearly improve the quality of road tests based evaluations. Thus, the fuel consumption rate is continuously recorded during the motion of the vehicle, whereas the power required to ensure displacement can be calculated using a simulation model with the data recorded during a path. Integrating over time the average power values at each interval, the energy necessary to ensure the vehicle displacement is calculated, while integrating the fuel rate over the duration of the path, the fuel consumption is computed. The ratio between the theoretically required energy and the one actually spent provides the conversion efficiency of the vehicle propulsion system. The developed tool is very useful in the framework of the courses about car dynamics included in Mechanical or Automotive Engineering Programmes. The developed tool couples data collected during road tests with a simulation model that computes all the force components acting on the car body during the motion. It has been written in LabView and an attractive graphical interface is used to keep the attention of the students when the data is displayed in real-time or analysed based upon previously recorded files.
\end{abstract}

Keywords - Energy conversion in vehicles, Data processing and display, LabView application tool, Software tool for road tests.

\section{Introduction}

In this paper is presented the work developed during a final thesis project of two students of a graduation program in Mechanical Engineering. The challenge was to develop and implement a methodology to allow the determination of the energy conversion efficiency of the propulsion system of a passenger car based upon the data 
collected in road tests. Complementarily, the communication of road tests results in an attractive manner, facilitating its interpretation, was also defined as a main target. Due to the nature of the work, the total budget had to be contained. Nevertheless, the objectives were also to improve the quality of the performed assessment, reducing the uncertainties through the correction of the main disturbances caused by the variability of wind conditions during the tests. Since most of the car road tests are performed by the automotive manufacturers, the results are not frequently published due to concurrence issues. Nevertheless, some papers with methods and results of on-road tests were found by the authors in a technical literature survey $[1,2,3,4,5,6]$.

\section{Theoretical Formulation}

The energy conversion efficiency of the propulsion system of a vehicle is the relationship between the energy needed to travel a path and the actual consumed energy. In a vehicle with an internal combustion engine, the total consumed energy is calculated multiplying the lower calorific value of the fuel by the consumed amount of fuel. This type of calculation can be performed either in the end of the travel, or for individual paths after a certain time interval.

Starting by the determination of the needed energy to ensure the movement, in the case of a vehicle traveling on the road, the motor torque is applied to the shaft via the transmission system and results on the force that the driving wheels transmit to the ground to ensure the movement. This force can be calculated by the following equation:

$$
F_{d r v}=R_{\text {rol }}+R_{\text {aerod }} \pm F_{\text {inerc }} \pm F_{\text {grav }}
$$

in which $\mathrm{F}_{\mathrm{drv}}$ is the driving force applied on the ground by the wheels, $\mathrm{R}_{\mathrm{rol}}$ the rolling resistance, $R_{\text {aero }}$ the aerodynamic drag, $F_{\text {inerc }}$ the inertial force and $F_{\text {grav }}$ the gravitational force. During acceleration periods, $F_{\text {inerc }}$ becomes positive, corresponding to a resistance, while in deceleration phases becomes negative, helping the movement. $F_{\text {grav }}$ is positive and represents a resistance when the vehicle is climbing, and is negative and helps the movement when the vehicle is going downhill.

In equation (2), each term of the second member of equation (1) is replaced by its analytical expression:

$$
\begin{gathered}
F_{d r v}=M \cdot g \cdot \cos \alpha \cdot\left(K_{0}+K_{1} v_{g r}{ }^{2}\right)+ \\
+\frac{1}{2} \cdot C_{x} \cdot \rho \cdot A \cdot v_{\text {air }}{ }^{2} \pm M \cdot a \pm M \cdot g \cdot \sin \alpha
\end{gathered}
$$

wherein:

$\mathrm{M}$ - vehicle mass [kg]

$\mathrm{g}-$ gravitational acceleration $\left[\mathrm{m} / \mathrm{s}^{2}\right]$

$\alpha$ - road slope angle $\left[^{\circ}\right]$

$\mathrm{K}_{0}$ - static friction coefficient [dimensionless] 
$\mathrm{K}_{1}$ - dynamic friction coefficient $\left[\mathrm{s}^{2} / \mathrm{m}^{2}\right]$

$\mathrm{v}_{\mathrm{gr}}-$ relative vehicle/ground velocity $[\mathrm{m} / \mathrm{s}]$

$\mathrm{v}_{\text {air }}-$ relative vehicle/air velocity $[\mathrm{m} / \mathrm{s}]$

$\mathrm{C}_{\mathrm{d}}$ - aerodynamic drag coefficient

$\rho$ - specific mass of air $\left[\mathrm{kg} / \mathrm{m}^{3}\right]$

A - frontal area of the vehicle $\left[\mathrm{m}^{2}\right]$

The instantaneous values of the total driving force can be calculated from the sum of terms in the second member of (2), using the characteristics of the test vehicle (total mass $\mathrm{M}$, drag coefficient $\mathrm{C}_{\mathrm{d}}$ and tire/road friction coefficients $\mathrm{K}_{0}$ and $\mathrm{K}_{1}$ ) the other terms in the equation, with the exception of $\mathrm{g}$ and $\rho$, being derived from the data collected by the on-board acquisition system during travels.

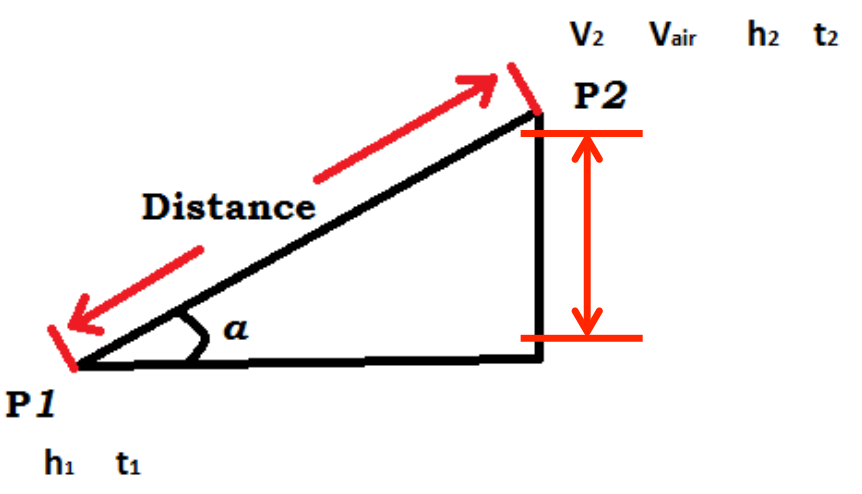

Fig. 1. Path between points $\mathrm{P} 1$ and $\mathrm{P} 2$

Since for each sampling moment of time the geographical coordinates (latitude, longitude and altitude), the vehicle speed and the dynamic pressure of the flow in the front of the vehicle are obtained, with the information for two consecutive points it is possible to calculate the road slope angle $(\alpha)$ and the speed of the vehicle relatively to the ground $\left(\mathrm{v}_{\mathrm{gr}}\right)$ and to the air $\left(\mathrm{v}_{\text {air }}\right)$, as exemplified in Figure 1. The distance between points $\mathrm{P} 1$ and $\mathrm{P} 2$ is calculated multiplying the duration of the sampling interval by the mean velocity:

$$
d=\frac{\left(v_{2}+v_{1}\right)}{2}\left(t_{2}+v_{1}\right)
$$

The road slope angle is calculated as:

$$
\alpha=\arcsin \left(\frac{h_{2}-h_{1}}{d}\right)
$$




\section{Experimental Methods}

The tests were carried out with a passenger car Renault Fluent $1.5 \mathrm{dCi}$, equipped with a $81 \mathrm{~kW}$ Diesel type internal combustion engine, belonging to the university car fleet. The measurement and data acquisition system mounted in the vehicle has been designed in order to allow the sampling of the fuel rate together with the main parameters that were considered to have a relevant effect on the displacement conditions. Thus, it has been considered essential:

- to have a complete definition of the traveled routes, i.e. the geographic coordinates (latitude, longitude and altitude), as well as the vehicle speed;

- to correct the disturbances due to the occurrence of wind during the journey;

- to gather the information available on the electronic central unit (ECU) of the vehicle motor, available through the on-board diagnostic (OBD) plug.

The schematic representation of the measuring and data acquisition system is shown in Figure 2.
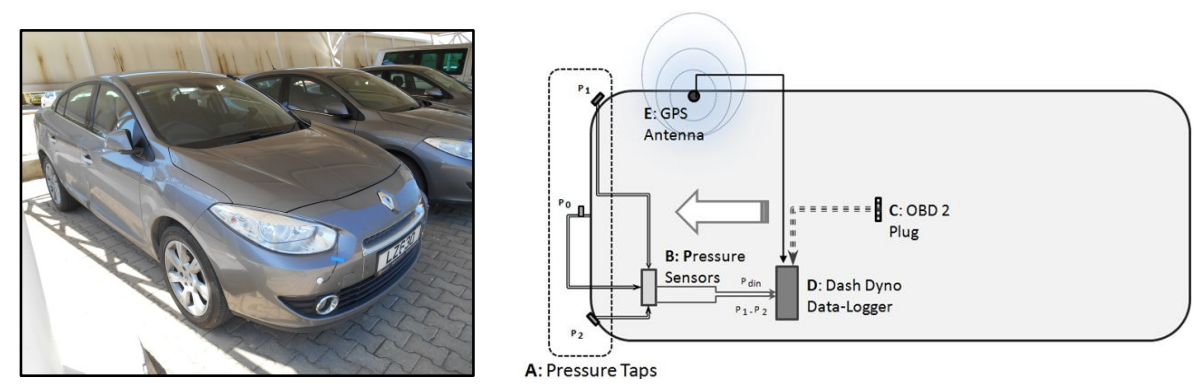

Fig. 2. Car used in the road tests and scheme of the monitoring system

The measuring system is composed by:
A: Pressure ports $\mathrm{P} 0, \mathrm{P} 1$ and $\mathrm{P} 2$;
B: Pressure sensors Omega PX163 and PX164;
C: OBD II plug;
D: Auterra Dash Dyno Data logger.

Since the GPS system of the Dash Dyno logger does not acquire the altitude values and they are fundamental to the implementation of the calculation model, a second GPS data logger (GlobalSat DG100) has been added to the monitoring system. It records the time tag, the latitude, the longitude, the altitude and the speed.

In Table 1, are identified the OBD II variables that were selected to be recorded in the Dash-Dyno logger. They were considered to be the most relevant to document the engine operation for further analysis. Channels 3 and 4 are not digital signals from OBD II plug and correspond to analog voltage signals that are received from the two pressure transducers connected to the pressure taps in the front of the vehicle. Channel 
3 is recording the dynamic pressure measured in the flow stagnation zone. It is acquired from subtracting the value of the static pressure from the stagnation pressure obtained from the P0 pressure tap. To evaluate the angularity of the flow due to the effect of crosswinds, the difference pressure between the P1 and P2 taps is recorded on channel 7.

Table 1. Channels of Dash-Dyno Data Logger

\begin{tabular}{|c|l|c|l|}
\hline Channel & \multicolumn{1}{|c|}{ Parameter } & Channel & \multicolumn{1}{c|}{ Parameter } \\
\hline 1 & GPS Speed & 9 & Fuel Rail Pressure \\
\hline 2 & Rotation Speed & 10 & Calculated Load \\
\hline 3 & Analog 1 Pdin ${ }^{\mathrm{a}}$ & 11 & Nr of GPS Satellites \\
\hline 4 & Analog 2 Dif P & 12 & GPS Hdop \\
\hline 5 & Fuel Rate & 13 & Air Flow Rate MAF \\
\hline 6 & Intake Air Pressure & 14 & Air Flow Rate MAP \\
\hline 7 & Coolant Temp & 15 & Throttle Position \\
\hline 8 & Vehicle Speed & 16 & Idle Time \\
\hline
\end{tabular}

Details of the installation of the pressure sensors box in the engine compartment are presented in Figure 3. A constant input voltage of 10 volt, obtained from the car battery tension passing through a voltage regulator, is used to supply the piezoresistive pressure sensors. In the same figure an image of the mounting of the 3 pressure ports in the front of the vehicle is also presented.
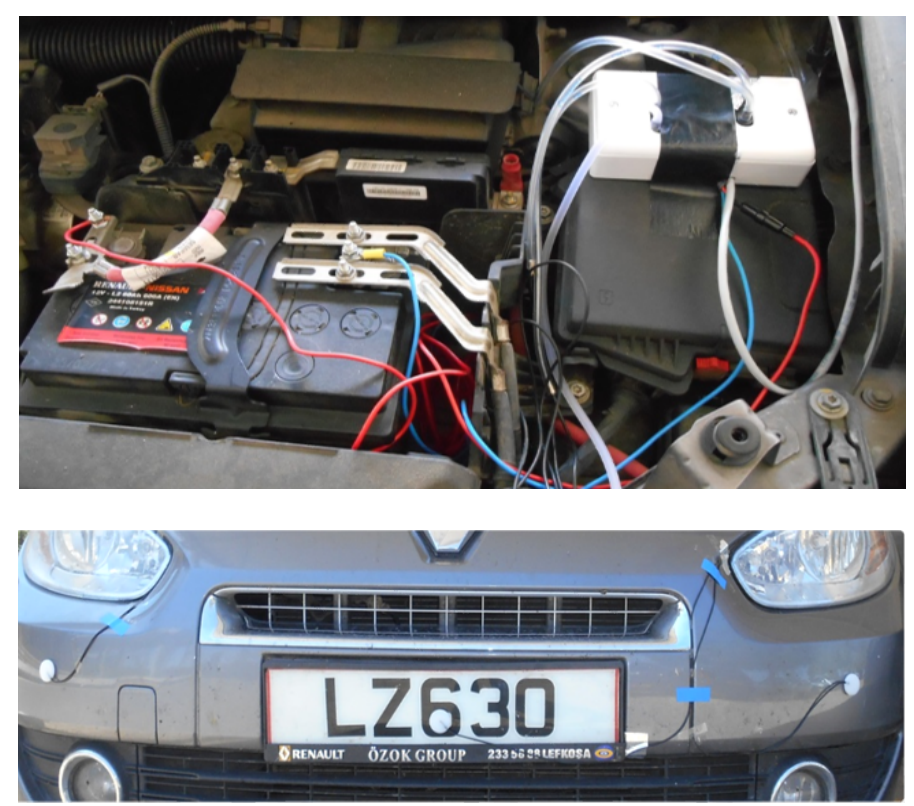

Fig. 3. Images of the pressure sensors box in the engine compartment and the pressure ports in the front of the car 
Images of the two data loggers mounted in the vehicle to register data during the road tests are presented in Figure 4.
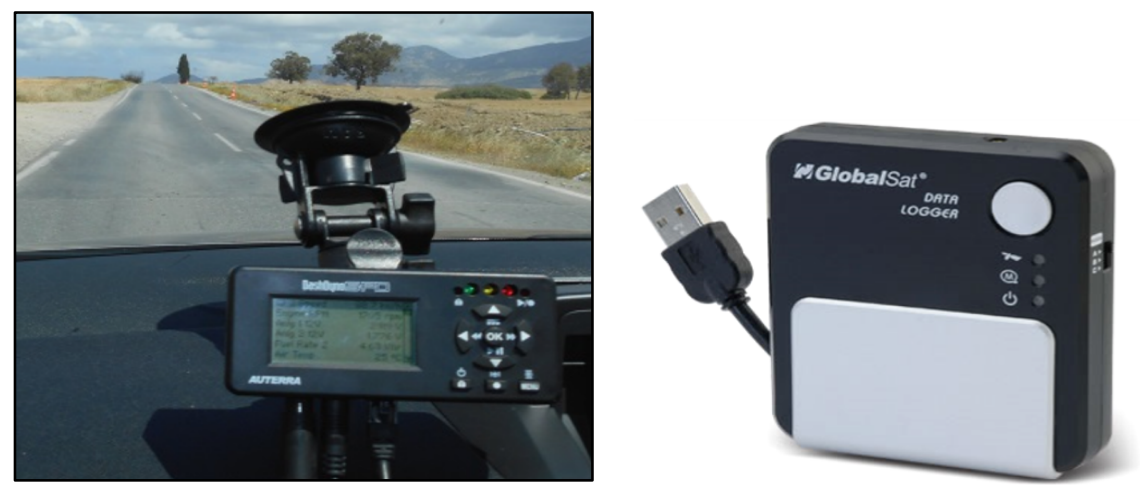

Fig. 4. OBD II Dash Dyno logger and GlobalSat GPS logger

In Table 2, the characteristics of the vehicle and the physical constant values are displayed. For the $\mathrm{Cd}$ and the frontal area values, the data delivered by the manufacturer in the available technical information has been used. The mass value was calculated summing to the technical catalogue value the mass of the passengers.

Table 2. Vehicle's Characteristics and Constants

\begin{tabular}{|l|c|}
\hline \multicolumn{1}{|c|}{ Parameter } & Value \\
\hline Mass $(\mathrm{kg})$ & 1634 \\
\hline Static friction coef $\mathrm{K}_{0}$ & 0.01 \\
\hline Dynamic friction coef $\mathrm{K}_{1}$ & 0.0000003 \\
\hline Specific mass of air $\rho\left(\mathrm{kg} / \mathrm{m}^{3}\right)$ & 1.225 \\
\hline Aerodynamic drag coef $\mathrm{Cd}$ & 0.32 \\
\hline Frontal area A $\left(\mathrm{m}^{2}\right)$ & 2.136 \\
\hline Acceleration of gravity $\mathrm{g}\left(\mathrm{m} / \mathrm{s}^{2}\right)$ & 9.81 \\
\hline
\end{tabular}

As regards the friction coefficients, the typical values presented in [1] were confirmed in a deceleration test.

\section{$4 \quad$ Results}

In Figure 5, the followed test route is depicted. Point 1 represents the beginning and end of the test. It is a gas station next to a Cypriot town named Bostanc1. To successfully complete a tank refill consumption method, the trip should start and finish at a gas station. Therefore, the test is completed by a closed circuit along that path. The geographical features of the route are very important for the experimental results. The first part of it consists mostly of flat roads. The second part is the path in Girne Moun- 
tains. Due to the curvy road and altitude changes, a lot of breaking events are required. Therefore this gives the perfect chance to analyze the effect of gravitational force and inertial force changes in the instantaneous values of the fuel rate. The last part of the path is the road between the mountains and the gas station and like the first part of the route, it consists mainly of flat roads.

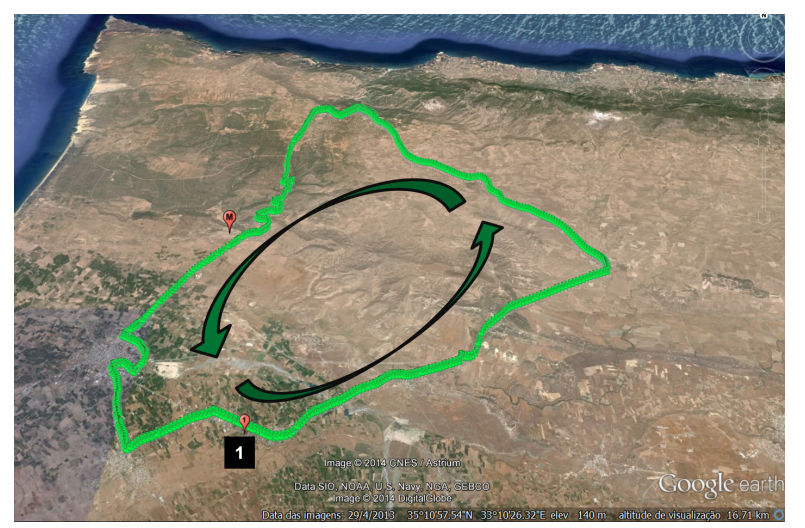

Fig. 5. Route followed during the tests in Google Earth platform

Figure 6 deals with the car fuel tank filling operation and the calibration of the gas station flow rate measuring systems. To check the uncertainty of this system, before filling the tank, the gas station employee was asked to fill with 1 liter measured by the gas pump a graduated burette.

An error of $1 \%$ has been detected, meaning that the actual volume should be obtained multiplying by 1.01 the value measured by the fuel pump flowmeter.

The GlobalSat DG-100 GPS Data Logger has been configured with a sampling interval of 5 seconds. A short path of recorded information is illustrated in Figure 7. Each green stamp represents a recording. If the distances between stamps are increasing, it means that the vehicle is accelerating and vice-versa. Each recording includes the time, current speed and current vehicle position (latitude, longitude and altitude).

The application tool developed in the LabView programming platform to visualize and analyze the data collected during the road tests is presented in Figure 8, showing in the various displays the data collected in the end of the performed test.
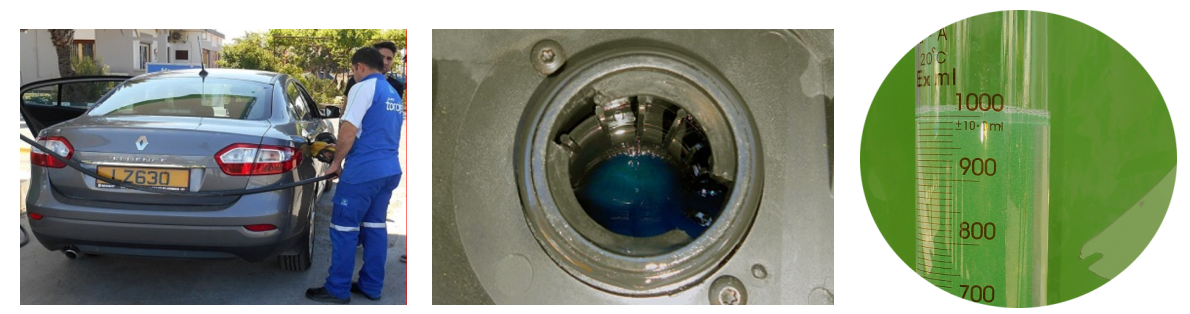

Fig. 6. Fuel tank filling and calibration of gas station flowmeter 


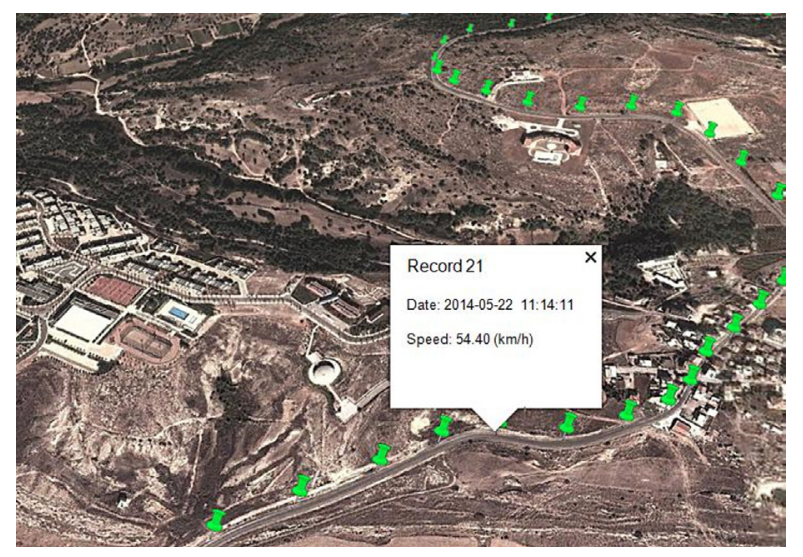

Fig. 7. Representation of the GPS acquired data points

It may be used either during the test, in case a laptop computer is collecting the information in real-time from the data-loggers, or to process previously recorded data files, showing, like a movie, the time evolution of the different parameters.

In the case of post-test visualization of data, the user can define in the upper left corner the rate at which the displays are refreshed, adjusting it depending on the total duration time of the test to be analyzed. In the left side of the screen, from top to bottom, are included: a speedometer with built-in odometer, a bar display showing the throttle position and two analog meters showing the air admission temperature and the engine coolant temperature.

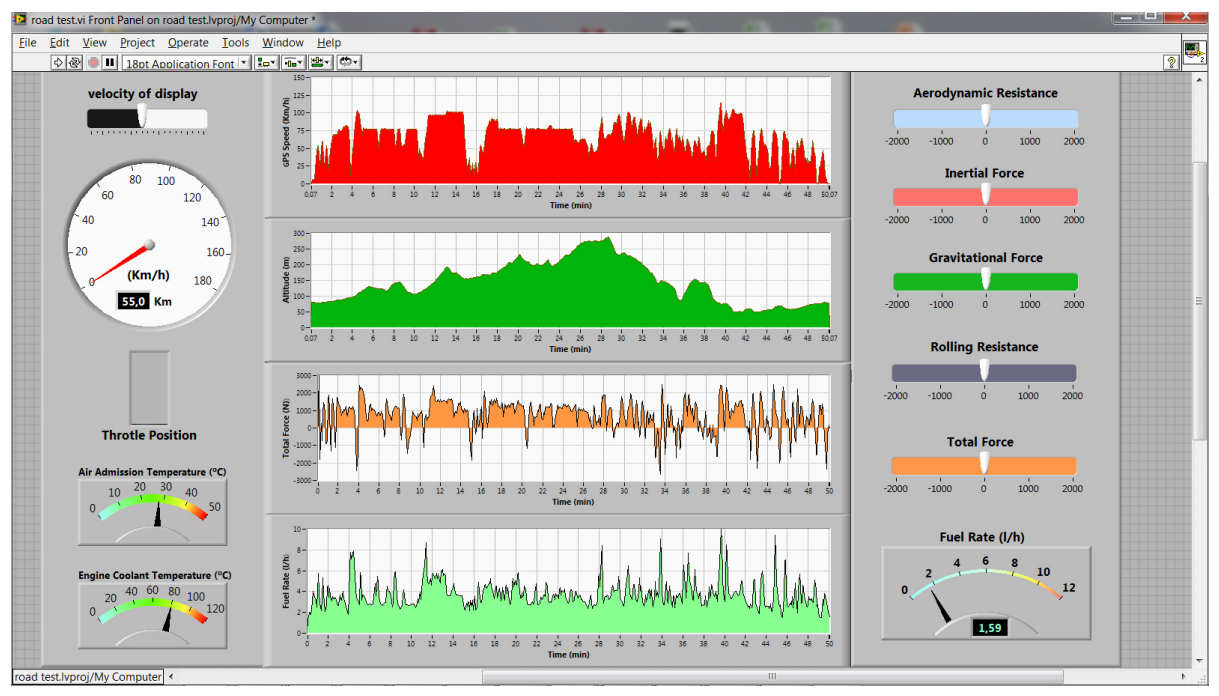

Fig. 8. Graphical interface of the application tool developed to display and analyze the road test data 
The central part of the screen is used to present four X-T graphs, from top to bottom: the car speed measured by the GPS in $\mathrm{km} / \mathrm{h}$, the altitude measured by the GPS in meters, the calculated driving in the car wheels and, finally, the fuel rate value calculated and available at the car electronic central unit (ECU).

In the right side of the screen, there are five slider displays showing the instantaneous values of the four force components in the second member of equation (1) and the instantaneous value of the driving force in the wheels (Total Force, corresponding to the sum of the four components). The instantaneous values of the fuel rate calculated by the ECU are displayed in the analog meter located in the lower right corner of the screen.

\section{Conclusions}

A methodology has been implemented coupling the results from the data acquisition system installed on-board of a car with the calculations of a simple model. Besides delivering the time evolutions of a larger number of parameters related with both the travel path and the vehicle operating conditions, it allows the determination of the energy conversion efficiency of the car propulsion system. The application tool developed to visualize the tests results is a precious auxiliary in teaching activities because it helps learners to establish the cause-effect relationship between the evolution of the path parameters and the force components participating in the vehicle motion equation. It may be used in two different ways: for post-processing of the files recorded by the data loggers in their internal memory or in a SD card; or as a realtime data processing and visualization tool. In the latter case, the vehicle road test experience may be converted into a remote access experience [7], in case a mobile internet connection is available in the car.

Exploring the same concept presented in [8], where the images of a webcam are displayed together with the results of a data acquisition process, a laptop computer running the application may act as a server using the web-publishing tools of LabView. In this way, all the students in a classroom may follow the evolution of the data collected while the car is tested on the road.

\section{Acknowledgment}

The authors acknowledge the METU-NCC administration services for lending the car used in the tests, as well as the driver services. The paper has been prepared in the framework of the project TRAPHIC (ref. POCI-01-0145-FEDER-016729 and PTDC/ECM-URB/3329/2014).

\section{$7 \quad$ References}

[1] V. Mickūnaitis, A. Pikūnas, I. Mackoit, "Reducing fuel consumption and $\mathrm{CO}_{2}$ emission in motor cars" Vilnius, Lithuania, May 2007 
[2] P. Roura, D. Oliu, “How energy efficient is your car?” American Journal of Physics, 588, 2002

[3] J. Merkisz, J. Pielecha, "Emissions and Fuel Consumption during Road Test from Diesel and Hybrid Buses under Real Road Conditions". Poznan University of Technology Institute of Internal Combustion Engine and Transport. 2009

[4] D. W. Kim, J. W Yoon, S. Park, K. Kim, T. Lee "Fuel consumption parameters for realizing and verifying fuel consumption prospect algorithm of vehicle driving route information system". International Journal of Automotive Technology, Vol. 14, No. 6, pp. 955-964. 2013https://doi.org/10.1007/s12239-013-0105-0

[5] M. Ghodsirad, J. Teixeira, P. Breda, C. Campos, L. Serrano, M. Gameiro da Silva "A Methodology to Evaluate the Performance and Consumption of Vehicles in Comparative On-Road Tests", Paper F2014-EDU-026 presented in FISITA 2014 World Automotive Congress, 2-6 June 2014, Maastricht, The Netherlands

[6] V. Pirs, Z. Jesko, J. Laceklis-Bertmanis. "Determination methods of fuel consumption in laboratory conditions". Engineering for Rural Development- 7th International Scientific Conference (s. 154-159). Jelgava: Latvian University of Agriculture, May 2008

[7] M. Teresa Restivo, M. C. Gameiro da Silva, "Portuguese Universities Sharing Remote Laboratories", Special Issue of International Journal on Emerging Technologies in Learning, November 2009, https://doi.org/10.3991/ijoe.v5s2.1090

[8] J. Dias Carrilho, M. Mateus, M. Gameiro da Silva, “ Real time web publishing of environmental noise monitoring data", 3rd Experiment@ internacional conference, June 2015, Ponta Delgada, Azores, Portugal

\section{Authors}

Manuel Gameiro da Silva (corresponding author) is Associate Professor in the Department of Mechanical Engineering of the University of Coimbra and has been Invited Professor at METU-NCC. He is the Coordinator of the Research Group in Energy, Environment and Comfort of ADAI-LAETA, the President of the Direction Board of the Portuguese Society of Engineering Education and Vice-President of REHVA (Federation of European Heating, Ventilation and Air Conditioning Associations).

Ahmet Gültekin graduated in Mechanical Engineering at the Middle East Technical University - North Cyprus Campus. He is Project and Coordination Engineer in Partner Teknik, Istambul.

Eren Ünlütürk graduated in Mechanical Engineering at the Middle East Technical University - North Cyprus Campus. He is Jr. Mechanical Engineer in VA Tech Wabag, Istambul.

Article submitted 22 November 2016. Published as resubmitted by the authors 13 February 2017. 